\title{
OVERVIEW OF ORGANOPHOSPHORUS COMPOUND POISONING IN BANGLADESH AND MEDICOLEGAL ASPECTS RELATED TO FATAL CASES
}

\author{
Ahmad M ${ }^{1}$, Rahman F N ${ }^{2}$, Ashrafuzzaman $\mathrm{M}^{3}$, Chowdhury DKP ${ }^{4}, \mathrm{Ali} \mathrm{M}^{5}$
}

\begin{abstract}
Introduction
Bangladesh is a developing country of South Asia. Rural population of this country is mostly dependant on agricultural cultivations. With the advance of times, pesticides are, now a days routinely used for modern cultivation method. These are readily available as over the counter (OTC) drugs in village shops and act as a common agent for suicidal purpose after trivial family problems. Currently pesticide self poisoning has become a major clinical problem of the developing countries ${ }^{1,2}$ killing around 3,00,000 people each year ${ }^{3,4}$. Industrialized countries are also affected by it, where a significant proportion of suicidal death are caused by Pesticide ingestion ${ }^{5,6}$. Of course, such poisoning is seldom included as a priority for heath research in this country.
\end{abstract}

\section{Background of Organophosphates and Uses}

During 19th century organo phosphates were first synthesized as chemical curiosities. In 1920 German chemist Gerhard Schrader started research for insecticides. By 1939, German Armed Forces stockpiled huge amount of Schrader's insecticides (Tabun) for using as Military nerve agents. At the same time Allies stockpiled DDT (Dichlor-diphenyl -trichloroethane), imported covertly from German chemical industry. The use of DDT substantially reduced the rate of morbidity from arthropod born diseases and also stopped epidemic of typhus in Naples in 1944. But at the same time, the indiscriminate use of DDT caused dramatic drop in bird population. Also pesticide accumulated in marine species, turning them into poisonous food for human consumption. Hence gradually the use of organo chlorine has been replaced by organo phosphorous compound (OPC).

Now a days OPCs are used as ship dips, military nerve agents, pour-ons in cattle farms, preservatives for crop and store grains, domestically as fly strips, wood worm preservatives, pet flea preparation and treatment of human arthropod infestation (malathion) etc ${ }^{7,8}$.

\section{The Fatality Related to OPC Poisoning}

Poisons may enter the body through different routes. The rapidity of action of a poison depends upon the route of administration, the rate of absorption and the mode in which it is introduced in to the system. In order of rapidity of action, the routes are as follows :- Inhalation in gaseous or vaporous form (During spraying of insecticides in the field, if proper precautions are not taken, then OPC in vaporous form can be inhaled with inspired gas); injection into the blood vessels; intramuscular, subcutaneous, intra dermal injection; Application to an open wound (handling OPC insecticides with bare handed, when there is open wound in the user's hand); application to a serous surface; application to broncho tracheal mucous membrane; introduction into stomach (when ingested for suicidal purpose); Introduction into natural orifice- rectum, urethra, vagina (as abortificients, village dais sometimes use OPC, datura, ergot, coleopteris, madar, yellow oliender etc); application to unbroken skin (OPC, nicotine, phenol \& its derivatives, etc) $)^{9}$.

Absorption through the stomach depends on some factors; as fullness of stomach, presence of pyloric stenosis. The toxic action of the poison depends on amount of the substance taken, its distribution to the tissues and also the rate of excretion from the body. With massive ingestion or inhalation, symptoms may appear within five minutes; or may be delayed to half to one hour and a maximum of 2 to 8 hours. Signs and symptoms appear, when the cholinesterase level drops to $30 \%$ of its normal activity. Very small amount of OPC are required to kill a person. The fatal doses of various OPC are shown in table- $\mathrm{I}^{9}$. The fatal period is usually within 24 hours in untreated

Table-I : Fatal doses of various organophosphorus compounds.

\begin{tabular}{|l|l|}
\hline Name of compounds & Fatal doses \\
\hline Tetraethyl pyrophosphate (TEPP) & $100 \mathrm{mg}$ \\
\hline Octamethyl pyrophosphoramide (ompa) & $175 \mathrm{mg}$ \\
\hline Parathion & $175 \mathrm{mg}$ \\
\hline Hexaethyl tetraphosphate (HETP) & $350 \mathrm{mg}$ \\
\hline Malathion, Diazinon & $01 \mathrm{gram}$ \\
\hline
\end{tabular}

cases and within 10 days if treatment is not successful. In nonfatal case, acute effect lasts for 6 to 30 hours, which disappear within 2 to 3 days. But it may persist for 2 weeks. Complete recovery occurs in 10 days in patients treated early. However rapid atropinization, stomach wash with 1: 5000 potassium permanganate solution, artificial respiration, oxygen inhalation, specific cholinesterase reactivator - pralidoxim iodide, antibiotic can save such a victim, if the treatment are given in time.

1. Maj Mushtaq Ahmad, MBBS, MCPS, DFM ; Graded Specialist \& Head, Forensic Medicine, AFMC, 2. Dr Farial Naima Rahman, MBBS, DMU, Practicing Sonologist ; 3. Col Mohd Ashrafuzzaman, MBBS, M,Phil, Head, Pharmacology, AFMC, 4. Lt Col Dipak Kumer Paul Chowdhury, MBBS, M.Phil, Associate Professor, Pharmacology, AFMC, 5. Lt Col Mohammad Ali, MBBS, DPH, M.Phil, Associate Professor, Community Medicine, AFMC 


\section{Causes and Mechanism of Death}

Death in case of organophosphorus poisoning is caused by paralysis of respiratory muscles, respiratory arrest due to failure of respiratory centre, or intense bronchoconstriction. In human body, traces of acetylcholine are produced at the myoneural junction, which is hydrolysed to choline and acetic acid simultaneously. Hydrolysis is greatly increased by cholinesterases (present in plasma, membranes and cytoplasm of many cells). Organophosphorus compounds are powerful inhibitors of carboxylic esterase enzymes, including acetylcholinesterase (found in the red cell, nervous tissue, skeletal muscle etc) and pseudocholinesterase (found in plasma, liver, heart, pancreas, brain ).

Organophosphorus compounds bind firmly to esterase enzyme, inactivating it by phosphorylation, at the myoneural junctions and synapses of the ganglion. Due to which acetylcholine accumulates at the parasympathetic, sympathetic and somatic sites and transfer of nerve impulses across synapses at the autonomic ganglia and nerve-muscle junction is prevented. Depolarizing of neuromuscular blocking produces a syndrome of overactivity of unhydrolysed acetylcholine ${ }^{10}$.

Organophosphorus compounds have action both on autonomic nervous system and central nervous system. On autonomic nervous system, they have parasympathomimetic action, and on central nervous system, the action is depressive. Speed of pesticides action on human body depends on their variety, such as parathion converts to paraoxon and cause a person to become unconscious within 10- 20 minutes, whereas dimethoate slowly converts to active oxon, omethoate \& poisoning develops after several hours ${ }^{11}$.

\section{Signs and Symptoms of OPC Poisoning}

OPC compounds have three distinct toxic effects on human body ${ }^{12,13}$.

Muscarine like effect : It potentiates postganglionic parasympathetic activity and causes bronchoconstriction, increase salivation, sweating, lacrimation, constriction of pupil, blurred vision, urinary incontinence, bradycardia, hypotension, etc .

Nicotinic effect : It causes paralysis of preganglionic and somatic motor nerves, resulting in twitching of facial muscles, eyelids, tongue, neuro muscular blockage .

Central nervous system : Restlessness, headache, tremor, drowsiness, ataxia, confusion, convulsion, respiratory depression, coma, death.

\section{Medico Legal Aspects of Death}

In Forensic Medicine all deaths are included in certain manners, namely; natural, suicidal, homicidal, accidental, sudden etc. Poisoning is most commonly accidental, but a large number are suicidal or in many cases are suicidal gestures. It is now the most common method of self destruction in advanced communities, due to easy availability of toxic drugs. In Britain, acetaminophen has

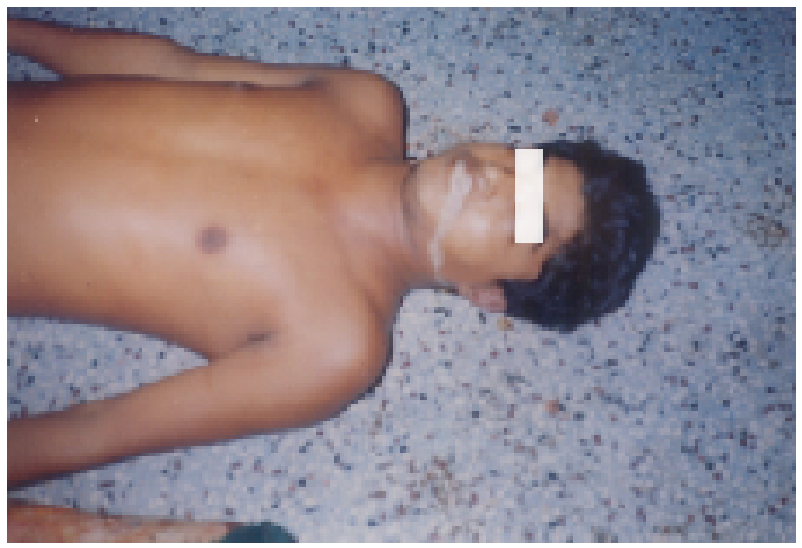

Fig -1: Blood stained froth in the mouth and nostrils of a victim of OPC Poisoning at DMC morgue.

replaced barbiturates and aspirin, as favourite methods of suicide. In South-East Asia, the availability of agricultural products such as paraquat, parathion and acetic acid for rubber preparation has made these substances more common. Opium and Barbiturate satisfy several of the criteria's as ideal suicidal poison. A study in India has shown that dichlorvos $(76 \% \mathrm{EC})$ is also used as injectable suicidal agent ${ }^{14-16}$.

In India OPC intake is the commonest method of suicide $(40.5 \%)$ after hanging $(49 \%)^{17}$. In the vast rural area of Bangladesh Organophosphorus compounds and endrin are commonly used as suicidal poison due to easy availability as insecticides, where as it is rare in urban $\operatorname{area}^{18}$. Accidental poisoning can vary from the individual case of a child eating medicinal tablets by mistake for sweets to mass industrial disasters such as Bhopal in India, the leakage of Dioxine gas in Italy or contaminated cooking oil in Spain, where in total claimed thousands of lives. Accidental poisoning occurs in manufacturers, packers, sprayers, users, children of users, and due to contamination of food grains mixed with insecticides preserved for seedling purposes. Poisoning also occurs from fruits and vegetables ${ }^{19}$. Homicidal poisoning by insecticides usually does not occur, since smell of the subject used as diluent (aromax) of the poison and also due to alarming signs and symptoms which appear rather early. Due to ease of detection, homicide by poisoning is now relatively rare in advanced countries. But it is more common in developing countries where public awareness and availability of diagnostic method is less. Most research performed in Bangladesh, have shown that Datura is the predominant agent, used for homicidal purpose $^{20}$.

\section{The Methods for Detection of Poison}

Toxicological analysis for biological tissues involve three stages: (1) Separation of poisonous substance from the biological tissue, (2) Purification of poisonous substance, (3) Analytical detection and quantization'. Detection of poisoning is usually based upon history given by patient's relatives. During clinical examinations and history taking, 
a doctor may detect staining of poison on victim's body. Peculiar smell of OPC (due to presence of aromax) is present in mouth and nostril area of the victim. Atropinization of patient and analysis of blood cholinesterase level plays very important role in diagnostic process. During post mortem examination, some viscera are preserved and sent to the chief chemical examiner's office, Dhaka for toxicological analysis. These includes (1) Whole of stomach with its content, (2) Portion of right lobe of liver, (500 grams), (3) Longitudinal section of half of each kidney. In special cases other specimen, like, blood, urine, brain, heart, lungs, etc are preserved. In Bangladesh, the only Chemical Examiners Laboratory is situated in the Institute of Public Health, Mohakhali, Dhaka. It is under the jurisdiction of Criminal Investigation Department (CID) of Bangladesh Police. Age old methods for detection of poisons are used here.

\section{Management of OPC Poisoning Cases}

Management of OPC poisoning cases includes 4 stages. (1) Initial stabilization of patient by maintaining respiration and other vital signs; (2) reduction of exposure, (3) administration of specific antidote, (4) supportive treatment ${ }^{21}$.

The initial objective of management is establishment of clear airway and adequate ventilation, because in OPC poisoning there is respiratory distress secondary to bronchospasm, increase respiratory secretion, pulmonary oedema etc. Patient is removed from source of exposure, contaminated clothings are removed and exposed areas are washed with soap and water. In case of ingested poison, stomach wash is given by $1: 5000$ potassium permanganate solution. Specific antidote includes atropine and pralidoxime. Atropine acts as a physiological antidote, which arrests the muscarinic effect of post ganglionic parasympathetic activity and CNS effect. In mild cases one ampoule $(0.6 \mathrm{mg})$ atropine sulphate is given by $\mathrm{I} / \mathrm{V}$ route every 5 - 30 minutes till atropinization (clear chest- no wheeze, no respiratory distress, pupil no longer pin pointed, dry axillae, heart rate $>80 / \mathrm{min}$, systolic blood pressure $>80 \mathrm{~mm}$ of $\mathrm{Hg}$ of the patient). In severe cases 2-5 mg atropine may be administered at 10 30 minutes interval till the patient improves. Pralidoxime is specific biochemical antidote for OPC poisoning. Oxime reactivates cholinesterase, remove block at neuro muscular junction, prevent function of phosphorylated enzymes and directly detoxify OPCs. Currently WHO recommend $30 \mathrm{mg} / \mathrm{kg}$ loading dose of pralidoxime over 10-20 minutes, followed by continuous infusion of $8-10$ $\mathrm{mg} / \mathrm{kg}$ per hour till recovery. Continuous 2- PAM infusion along with aggressive atropinization after initial decontamination improved the outcome of mechanical ventilation in severely intoxicated patients. If Obidoxime is available, a loading dose of $250 \mathrm{mg}$ is given followed by an infusion giving $750 \mathrm{mg}$ every 24 hour, till patient improves. Obidoxime crosses blood brain barrier more than pralidoxime. Diazepam 10-20 mg in adult and 0.25-
$0.5 \mathrm{mg} / \mathrm{kg}$ in children are also given to counter act CNS effect, relieve of anxiety, antagonizing convulsions and to improve morbidity and mortality. Other supportive treatment includes oxygen inhalation, maintenance of circulation, treatment of convulsion, fluid \& electrolyte balance, control of infections, maintenance of nutrition and control of body temperature ${ }^{22-26}$.

\section{Post Mortem Findings in Death Cases}

During post mortem examination cyanosis is usually found in lip, finger, nose of the victim. Blood stained froth is found in mouth and nostrils. The peculiar smell of OPC is again detected in stomach contents. All the internal organs are congested, since death occurs in most cases due to respiratory failure. Sub mucosal petechial haemorrhage is found in stomach. Excessive oedema and subpleural petechial haemorrhage are present. Heart is soft and flabby. Brain is also congested and oedematous ${ }^{27}$.

\section{OPC Poisoning Situation in Bangladesh and other} Countries

A study performed at Rajshahi Medical College from January 1991 to December 1994 showed that among 405 cases of poisoning, OPC poisoning was the commonest one $(38.8 \%)$, followed by poisoning with sedative (29.1\%). Out of those 405 cases; 310 were suicidal (76.54\%) and 95 were homicidal $(23.45 \%)^{18}$. Similar study preformed in Urban area like Dhaka Medical College showed that for suicidal purpose, sedative poisoning is the commonest followed by OPC poisoning ${ }^{28}$. Study performed at Dhaka Medical College from January 2004 to December 2004 showed that out of 4378 admitted patients $40 \%$ were male an $60 \%$ were female. $44 \%$ patient came from urban area, while $56 \%$ from rural area. Incidence was high among students (35\%), followed by house wives (30\%). Most common reason for poisoning was suicide $(93.3 \%)$ and sudden anger was the commonest drive $(53.3 \%)$. However a study done in paediatric ward at Sir Salimullah Medical College, showed that in case of children, all the cases of poisoning were accidental in nature ${ }^{29}$. Another study at Dhamrai Thana Health Complex performed from January 1993 to December 1997 showed that males ( $61.30 \%)$ were predominant than females $(38.70 \%)$ in poisoning cases. Acute poisoning was observed more in married group $(68.64 \%)$ than unmarried group $(31.36 \%)$.Commonest poisoning agent was insecticides $\mathrm{OPC}^{30}$

Epidemiological work from Spain supports link between chronic OPC exposure and increased suicidal rate $^{31}$. Chronic exposure to OPC also gives rise to a condition called COPIND- Chronic Organo Phosphate Induced Neuro-psychiatric Disorder ${ }^{32-34}$. Genetic differences also play important role in Chronic OPC poisoning cases $^{35}$.

Present scenario of OPC poisoning in Bangladesh is alarming. Farmers of this country use pesticides without knowing their harmful side effects. 15,376 M Ton of pesticides were sold in this country during 2001, which 
increased to $37,712 \mathrm{M}$ Ton in 2007; a rise of $145.26 \%$. According to Bangladesh Crop Protection Association (BCPA), 61 member companies import, distribute and sell pesticides in this country. According to Plant protection wing of Department of Agriculture, the number is 153 . Organo phosphate, ogano carbamate and synthetic pyrithroid are used as most popular pesticides in Bangladesh. After application in the field, there is a residual period for this insecticide, during which crops should not be consumed. This period varies from 4- 5 days for synthetic pyrithroids, 13- 35 days for organo carbamate and 11- 27 days for organophosphates. But farmers harvest and sell vegetables from the field just after next day of spraying insecticides. This causes serious harmful effects to human body giving rise to complications like cancer, mental disturbance, infertility, GIT disturbance, liver and kidney failure etc. In western countries every vegetable is checked for maximum residual limit (MRL) of insecticides, but it is not followed in Bangladesh. Due to indiscriminate use of insecticides, useful insects, birds, animals and fishes are killed. Even good micro organisms from upper 6-8 inches of soil are destroyed, making land infertile and prone to various diseases for crops.

Any person from age 15 to 55 years can obtain pesticide sales permission by paying only taka 75 as government fees. No educational back ground is required for this. However the Government has amended the pesticide rule in mid 2007 allowing bio technological pest control process, which includes control by sex hormone feromone. It has been seen by using chemical pesticides in one hector of land at a cost of taka $65,000 /-$, only $50 \%$ good brinjal are harvested, where as by using environment friendly sex hormone feromone trap in the same land at a cost of 12,000 taka, $90 \%$ healthy brinjal can be harvested. Recently 4 eco friendly steps have also been taken to solve insecticides related problems, preservation of useful insects and animals, cultivation of insect resistant high breed variety crops, modern cultivation method by using good seeds, fertilizer, irrigation etc and control of insects by using integrated pest management, light trap, hand net, etc ${ }^{36}$.

Study from Chandigarh Medical College, India (19701979 ) showed that out of 312 cases of poisoning $30.12 \%$ were barbiturate poisoning, $19.23 \%$ organo chemicals and $17.95 \%$ metallic irritants and corrosive ${ }^{37}$. During 19801989, another 555 cases of poisoning were reported from the same region and $31.35 \%$ fatalities were attributed to aluminium-phosphide, $27.03 \%$ to organophosphates and carbamates, $8.83 \%$ to barbiturates and $9.36 \%$ to metallic irritants and corrosives ${ }^{38}$. A total of 1035 cases of acute poisoning were studied during 1983 to 1996 at All India Institute of Medical Sciences, New Delhi and the trends showed the increasing use of agro-chemicals ${ }^{39}$.

Yet another study from Rohtak, India in 1993-1994 analyzed 559 cases of poisoning ${ }^{40}$ and Aluminium Phosphide was found to be the most common poison. The studied scenario was not different from these reports and agrochemicals continue to be the most common agents responsible for suicidal and/or accidental poisoning ${ }^{41}$. According to National Crime Records Bureau India, every 5 minutes a person commits suicide and 7 attempts to kill themselves, forming about $1,00,000$ death per year $^{42}$. Suicide rate was highest in the state of Kerala ${ }^{43}$. Majority of the victims belonged to the group 14- 34 years $^{44}$ and OPC was the most common agent used for suicide purpose ${ }^{45}$. In Sri Lanka, many thousands of hospitals admissions each year are for agrochemical poisoning, (16,649 in 1983) with over a thousands death annually (1521 in 1983). Of these, about three quarter are self administered, the remainder being occupational and accidental $^{46,47}$. In Sri Lanka, another study showed, incidence of suicide due to poisoning was more than 80 $\%$, followed by hanging, which constituted $10.7 \%{ }^{48}$. However changing use from the most toxic pesticides to less toxic pesticides has had a remarkable effect in Sri Lanka and the suicide rate has fallen by $50 \%$ over ten years since such legislation was passed ${ }^{49,50}$. In USA, during 1980, out of total fatalities $49.7 \%$ were suicides and $39.5 \%$ were accidental. The overall suicide rate changed little between 1970 and 1980 as the rate among young persons increased and women preferred firearms than poisoning to commit suicide ${ }^{51,52}$.

\section{Conclusion}

Bangladesh is an agrobased country. Suicide by agrochemical compounds are increasing day by day in this country. Illiteracy is a major problem to deal with the situation. Proper emphasis should also be given for safe use of pesticides to avoid accidental poisoning. Detail study regarding death due to organo phosphorus compounds poisoning is required to be carried out in this country.

\section{References}

1. Jeyaratnam J. Acute pesticide poisoning: a major global health problem. Wld Hlth Statist Q 1990, 43:139-144.

2. Eddleston M. Patterns and problems of deliberate self-poisoning in the developing world. Q J Med 2000, 93:715-731.

3. Eddleston M, Phillips MR. Self poisoning with pesticides. BMJ 2004, 328:42-44.

4. Buckley NA, Karalliedde L, Dawson A, Senanayake N, Eddleston M. Where is the evidence for the management of pesticide poisoning - is clinical toxicology fiddling while the developing world burns? J Toxicol Clin Toxicol 2004, 42:113-116.

5. Bruyndonckx RB, Meulemans AI, Sabbe MB, Kumar AA, Delooz HH. Fatal intentional poisoning cases admitted to the University Hospitals of Leuven, Belgium, from 1993 to 1996. Eur J Emerg Med 2002, 9:238-243.

6. Langley R, Sumner D. Pesticide mortality in the United States, 19791998. Vet Hum Toxicol 2002, 44:101-105.

7. Davies R, Ghouse A, Tegweed F. Chronic exposure to Organo phosphates : background and clinical picture. Advances in Psychiatric Treatment 2000; 6: 187-192.

8. Kasper D L, Braunwald E, Fauci A S, Hausar S L, Longo D L, Jameson J L. Principles of Internal Medicine. Vol-1. 16th ed. New York : Mc Graw Hill; 2005 .p. 1292-1294.

9. Reddy, Dr. K. S. Narayan. The Essentials of Forensic Medicine and Toxicology. 25th ed. India : Medical Book Coy; 2006. p. 428.

10. Taylor P. Anticholinestrase agents. In: Goodman LS, Gilman A, editors. The Pharmacological Basis of Therapeutics, 6th ed. New York : MacMillan Publishing Co; 1980.p.100 - 119. 
11. Buratti FM, Testai E. Evidences for CYP3A4 autoactivation in the desulfuration of dimethoate by the human liver. Toxicology 2007 ; 241:33-46.

12. Namba T, Nolte CY, Jackirel J, Grob D. Poisoning due to organo phosphorus insecticides: acute and chronic manifestations. Am J Med. 1971; 50: 475.

13. Rang HP, Dale MM, Ritter JM, Moore PK. Pharmacology. 5th ed. London : Churchill Livingstone, 2003.p.157-160.

14. Carson DJ, Carson.ED. The increasing use of Paraquat as a suicidal agent. Forensic Sci 1976. 7;151-60.

15. Raina S, Mahesh D M, Sood V, Kaushal S S, Gupta D. Self injection of Dichlorvos, an Organophosphorus Compound. OJHAS 2008;7(2):01-03.

16. Parkinson.C. The changing patern of paraquat poisoning in man. Histopathology 1980; 4: 171-183.

17. Prasad J. Rates and factors Associated with Suicide in Kaniyambad Block, Tamil Nadu, South India; 2000-2002. Int Journal of Psychiatry 2006. 52(1): 65- 71.

18. Azhar MA, Taimur AKM, Rafiqueuddin.AKM. Pattern of poisoning and its Mortality in Rajshahi Medical College Hospital. J Medical Teachers Federation 1996; 1(2): 56.

19. Lu C, Barr D B, Barr, Pearson M A, Waller LA. Dietary Intake and Its Contribution to Longitudinal Organo phosphorus Pesticide Exposure in Urban/Suburban Children. .Environ Health Perspectives 2008; 116 (4) :537- 542 .

20. Khan NI, Sen.N, Haque NA. Poisoning in a Medical Unit in Dhaka Medical College Hospital in 1993. Bangladesh Med J 1985; 14 (1): 9- 12. 21. WHO. Training Manual on Management of Poisoning Guideline2007; National Poison Information Center, WHO: Dhaka Medical College; 2007.p. 4-27.

22. Eddleston M, Dawson A, Karallidde L, Dissanayake W, Hittarage A, Azher S, Buckley N A. Early management after self poisoning with an organo phosphorus or carbamate pesticide- a treatment protocol for junior doctors. 2004. Critical Care 2004; 8 : R391- R 397.

23. Peter E. The role of Oximes in the Management of Organophisphorus Pesticide Poisoning. Toxicological Reviews 2003; 22(3): 165-190.

24. Boon N A, Colledge N R, Walker B R, Hunter J A A. Davidson's Principles \& Practice of Medicine. 20th ed. India : Elsevier; 2006.p. 216-220.

25. Eddleston M, Buckley NA, Eyer P, Dawson AH. Medical management of acute organophosphorus pesticide poisoning. Lancet $2008 ; 371: 597-607$

26. Bawaskar H S, Joshi S R. Organo phosphorus poisoning in Agricultural India- Status in 2005. JAPI 2005; 53 : 422-424.

27. Nandy, Apurba. Principles of Forensic Medicine. 2nd ed. India : Central Book agency; 2001. p. 439-494

28. Ahmed R, Shah R, Amin MMM, Parveen.S, Dey DK. Pattern and Mortality Rate of poisoning in Dhaka Medical College Hospital. J Medical Teachers Federation 1995; 1(1): 10-12.

29. Rahman.MS, Mollah MH, Kundu NC. Acute Childhood Poisoning in a teaching hospital. TAJ (Rajshahi) $1995: 6$ (2):77-78

30. Rahman MH, Samad MA. An epidemiological Study on Acute Poisoning in a rural Hospital of Bangladesh. JOPSOM 2000; 19(1), 40-46 31. Parron T, Hernandez A.T, Villanueva E . Increased risk of suicide with exposure to pesticides in an intensive agricultural area. A 12 year retrospective study. Forensic Science Internal 1996. 79 : 53-63.
32. Ahmed G M, Davies D R. Chronic Organo phosphates exposure : toward the definition of a neuro psychiatric Syndrome . Journal of Nutritional and Environmental Medicine 1997; 7 : 169- 176.

33. Davies DR, Ahmed G M, Freer T. Chronic organo phosphates induced neuro psychiatric disorder ( COPIND)result of two postal questionnaire surveys. Journal of Nutritional and Environmental Medicine 1999; 9:123- 134.

34. Jamal G A. Neurological syndrome of organo phosphorus compounds. Adverse Drug Reaction and Toxicological Review 1997; 16: $133-170$.

35. Yaamasaki Y, Sakamoto K, Watada H . The arg 192 isoform of paraoxonase with low sarin hydrolyzing activity is dominant in the Japanese. Human Genetics, 1997, 101, 67-68.

36. Hossain S, Riad M. Indiscriminate use of chemical pesticides. The Daily Prothom Alo 2008 July 20.p. 01-20.

37. Singh S, Sharma B.K, Wahi P.L. et al. Spectrum of acute poisoning in adults (10 year experience). JAPI 1984; 32: 561-563.

38. Singh S, Wig N, Sharma BR, et al. Changing pattern of acute poisoning in adults. JAPI 1997; 45: 194-197.

39. Aggarwal P, Handa R, Wali JP. Common poisoning in India; Proceedings of National Workshop on Practical and Emergency Toxicology 1998; (1): 09-15.

40. Siwach SB, Gupta A. The profile of acute poisoning in Haryana. JAPI 1995; 43:756-759.

41. Sharma BR, Harish D, Sharma V. Poisoning in Northern IndiaChanging Trends, Causes and Prevention Thereof. Med Sci Law 2002; 42(3): 251-257.

42. Baby S, Haridas M P, Yesudas K F. Psychiatric diagnosis in attempted suicide 2006. Calicut Med Journal 2006; 4(3) : e2.

43. Indrayan A, Wysocki M J, Kumar R, Chawla A, Singh N. Estimates of the years of life lost due to the top nine causes of death in rural areas of major states in India in 1995 Nat Med J of India 2002; $15: 1$.

44. Kandamuthan M. Preliminary findings on the psychosocial factors for attempt of suicide in Kerala. NIMHANS Journal 1998; 1: 261-270.

45. Galgali R B, Sanjeeb R, Ashok M V, Appaya P, Srinivasan K. Psychiatric diagnosis of Self Poisoning cases ; A general Hospital study. Indian Journal of Psychiatry 1998; 40(3); 254- 259.

46. Knight, Bernard. Saukko. Pekka. Knight's Forensic Pathology. 3th ed. London : Arnold; 2004. p. 566-569.

47. Karalliede L, Senanayake N. Acute organophosphorus insecticides poisoning in Sri Lanka. Forensic Sci Int 1988; 36: 97-100.

48. Hettiarachchi J, Kodithuwakka GCS, Chandrasiri N. Suicide in Southern SriLanka. Medicine, Science and Law 1988; 28 (3): 248-251. 49. Gunnell D, Fernando R, Hewagama M, Priyangika WDD, Konradsen F, Eddleston M. The impact of pesticide regulations on suicide in Sri Lanka. Int J Epidemiol 2007;36:1235-42.

50. Eddleston M. The pathophysiology of organophosphorus pesticide self poisoning is not so simple. Netherlands J Med 2008; 66(4):146- 148. 51. Rao NG. Textbook of Forensic Medicine and Toxicology. 1st ed. India : Jaypee; 2000.p. 333-335.

52. Klein-Scwartz W, Smith GS. Agricultural and Horticultural chemical poisoning: Morbidity and mortality in United States. Ann Emerg Med 1997; 29: 232- 238. 